Article

\title{
Impact of Climate Change on Runoff in the Gilgel Abbay Watershed, the Upper Blue Nile Basin, Ethiopia
}

\author{
Hailu Sheferaw Ayele ${ }^{1,2}$, Ming-Hsu Li ${ }^{1, *}$, Ching-Pin Tung ${ }^{3}$ and Tzu-Ming Liu ${ }^{3}$ \\ 1 Graduate Institute of Hydrological and Oceanic Sciences, National Central University, \\ Taoyuan 32001, Taiwan; hailu84@yahoo.com \\ 2 College of Science, Bahir Dar University, Bahir Dar, Ethiopia \\ 3 Department of Bioenvironmental Systems Engineering, National Taiwan University, Taipei 10617, Taiwan; \\ cptung@ntu.edu.tw (C.-P.T.); tedliu13@gmail.com (T.-M.L.) \\ * Correspondence: mli@cc.ncu.edu.tw; Tel.: +886-3-422-2964
}

Academic Editor: Arjen Y. Hoekstra

Received: 30 May 2016; Accepted: 29 August 2016; Published: 3 September 2016

\begin{abstract}
Hydrological assessment is critical to the successful implementation of adaption measures. In this study, projections of seven global circulation models (GCMs) associated with high and medium-low Representative Concentration Pathways (RCP 8.5 and RCP 4.5) for the period 2021-2040 and 2081-2100 were adopted to assess changes on runoffs in the Gilgel Abbay watershed, the upper Blue Nile basin. A weather generator was employed to generate daily temperature and precipitation to drive a hydrological model for impact assessment. Despite the projected magnitude of changes varied among different GCMs and RCPs, increasing runoffs in wet-season and decreasing in dry-season are observed in both periods, mainly attributed to the change in projected precipitation. Such changes are profound in cases of RCP 8.5 with respect to those of RCP 4.5 and in cases of 2081-2100 with respect to those of 2021-2040. Although the increasing runoffs would provide greater inflow to Lake Tana, the increase of precipitation in wet-season would imply a higher possibility of flash floods. On the other hand, decrease runoffs in dry-season further intensify existing shortage of irrigation water demand. These changes will have deleterious consequences on the economic wellbeing of the country and require successful implementation of adaption measures to reduce vulnerability.
\end{abstract}

Keywords: climate change; RCPs; Gilgel Abbay watershed; precipitation; runoff

\section{Introduction}

Climate change is unequivocal [1]. The increased concentrations of $\mathrm{CO}_{2}$ and other greenhouse gases in the atmosphere since 1750 have comprised the prominent cause of climate change. The combined global land and ocean surface temperature has increased by $0.85{ }^{\circ} \mathrm{C}\left(0.65^{\circ} \mathrm{C}\right.$ to $\left.1.06^{\circ} \mathrm{C}\right)$, over the period from 1880 to 2012. Across much of Africa for example, projections based on the high Representative Concentration Pathway $(\mathrm{RCP})$ suggest that a mean annual temperature peak will occur in mid-century and could reach $3{ }^{\circ} \mathrm{C}$ and $6{ }^{\circ} \mathrm{C}$ by the end of the 21st century [2]. This increase in air temperature is expected to facilitate the global hydrological cycle. Precipitation and evapotranspiration are the major hydrological components affected and will subsequently influence global and regional water availability. However, vulnerabilities to climate change vary regionally [3]. Frequent and adverse consequences will be felt by low income east African countries due to their topographical settings and poor adaptation capacity $[4,5]$. The impact is expected to be greater on surface water in east Africa, for example Lake Victoria and Lake Tana [6]. In particular, the Lake Tana basin may experience a 
negative change in water balance in the forthcoming decades due to climate change as well as over abstraction of water resources [7]. The study of hydrological changes occurring at local and regional levels is necessary in order to adapt to the current situation and changes in water resources that might occur due to climate change.

Currently many of the climate change impact studies on watershed hydrology are based on consideration of up to date emission scenarios of RCPs from the Coupled Model Intercomparsion Project Five (CMIP5) of Intergovernmental Panel for Climate Change (IPCC) [2] which include changes in precipitation, temperature along with the potential evapotranspiration, streamflow, and soil moisture [5,8,9]. Mbaye et al. [4] studied the impact of climate change on water resources in the upper Senegal Basin, West Africa using RCP 4.5 and RCP 8.5. They found a general decrease of runoff, evapotranspiration, and soil moisture under the two RCPs in all simulations with the declines being higher under the high-impact RCP. Beyene et al. [10] found that changes in precipitation combined with changes in potential evapotranspiration would increase streamflow of the Nile river basin during 2010-2039 but there would be a decline in during 2040-2069 and 2070-2100 time windows with the Special Report on Emissions Scenarios (SRES) of the Fourth Assessment Report (AR4) [1]. On the other hand, Setegn et al. [7] projected a uniform increase temperature in Lake Tana Basin in all the 15 GCMs for all time periods and emission scenarios based upon SRES of AR4 [1]. According to them for the SRES A2 scenario, four out of the nine GCMs showed significant decline in annual streamflow for the 2080-2100 period. Abdo et al. [11] assessed the impact of climate change on the inflow to Lake Tana using the statistical downscaling model (SDSM) and HBV hydrological models (Hydrologiska Byråns Vattenbalansavdelning). They found significant changes of seasonal and monthly flows. A reduction in the runoff volume during the wet-season by approximately $11.6 \%$ and $10.1 \%$ was predicted for the 2080s by the A2 and B2 emission scenarios of AR4, respectively.

Many past studies have implied that climate change will have potential impacts on watershed hydrology and have also predicted future changes in the runoff of Gilgel Abbay, which is the most important inflow contributing river into Lake Tana. Clearly what happens to this river is increasingly important in view of climate impact. Most findings of past studies are mainly based on the SRES of AR3 [12] and AR4 [1]. The application of updated emission scenarios is essential to make the impact assessments more reliable and valid.

The main purpose of this study is to assess the potential impact of climate change on runoff in the Gilgel Abbay, Tana basin, the upper Blue Nile basin by considering the up to date greenhouse gas (GHG) emission scenarios under two RCPs: RCP 4.5 (Medium-low) and RCP 8.5 (high). Historical daily precipitation and temperature were resampled by a weather generator to drive the General Watershed Loading Function (GWLF) [13] hydrological model to obtain the baseline streamflow. Differences in monthly temperature and ratios in monthly precipitation projected by GCMs in CMIP5 [2] were adopted to generate daily weather as inputs of the GWLF to obtain future streamflow to conclude quantitative impact assessments.

\section{Materials and Methods}

\subsection{Study Area}

The location of Lake Tana basin is shown in Figure 1, and the shaded region indicates the Gilgel Abbay watershed with elevations from $1791 \mathrm{~m}$ to $3510 \mathrm{~m}$ above sea level. About $90 \%$ of the water inflow to Lake Tana is from four major rivers (i.e., Gilgel Abbay, Gumara, Ribb, and Megetch Rivers). Gilgel Abbay contributes $28.5 \%$ of total inflows to the lake and is the largest contributor. Lake Tana is the largest lake in Ethiopia and the third largest lake in the Nile basin countries with a lake area of $3041 \mathrm{~km}^{2}$ and a maximum water depth of $14 \mathrm{~m}$. The Tana basin with a total area of $15,100 \mathrm{~km}^{2} \mathrm{has}$ national and regional significance. At a national level, it has great potential for irrigation water supply, hydroelectric power generation, crop production, livestock production, and ecotourism. Particularly, it is a main water tower for the Tis Abay I and II and Tana Belse hydropower plants currently under 
operations with a total size of 84 and 460 megawatts for the country, respectively [14]. At a regional level, the lake is the source of the Blue Nile, which contributes $80 \%-85 \%$ of the inflow to the Nile [15] and the expected water tower for the Ethiopia's Grand Renaissance Dam on the Blue Nile. Fluctuations in Gilgel Abbay inflow due to climate change will have a significant influence on the Lake Tana water balance. In addition to its inflow contribution to this lake, the Gilgel Abbay area is also home town to a population of over one million [16], which is entirely dependent on subsistence agricultural activity.

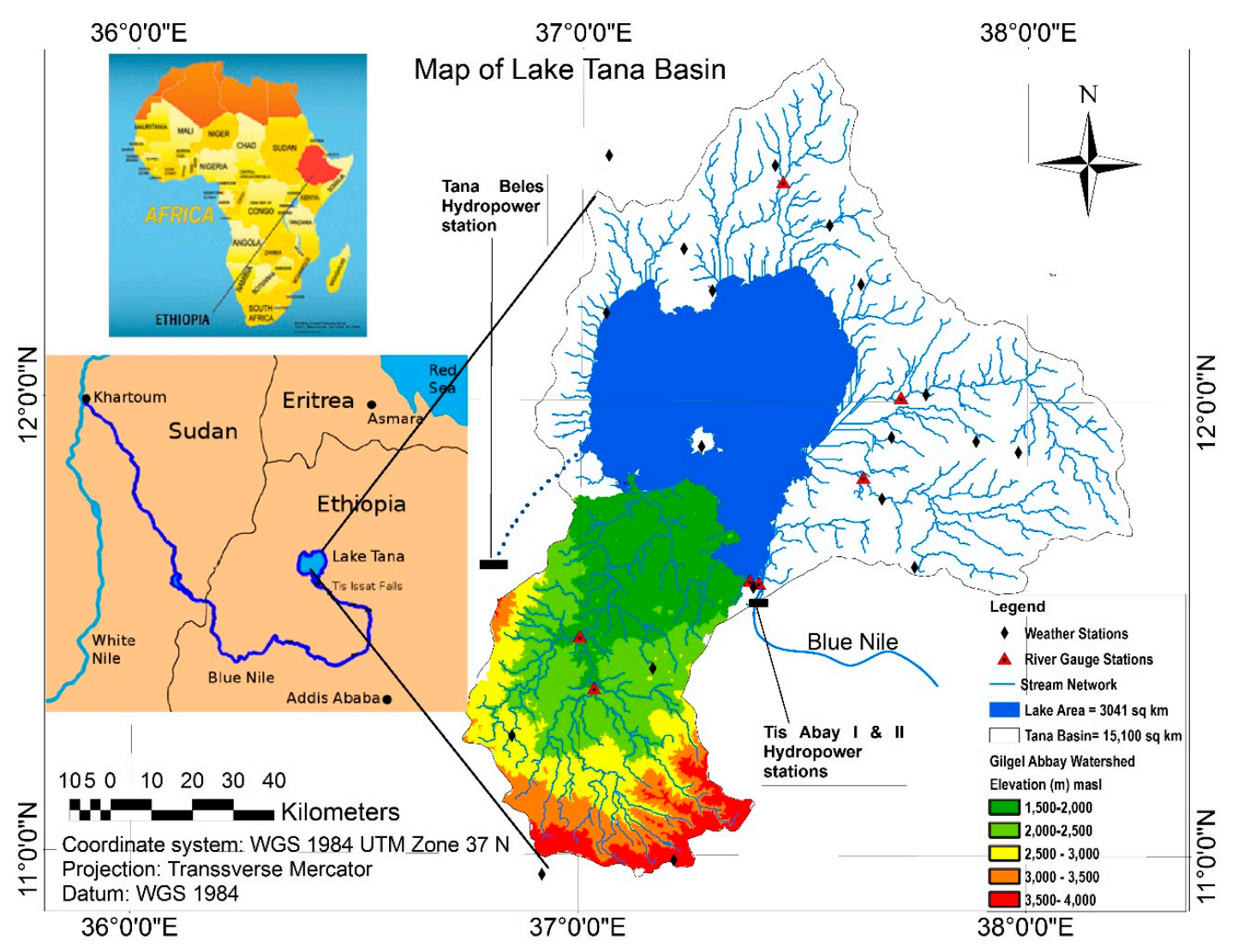

Figure 1. Location of study area, streamflow and metrological stations of Lake Tana Basin.

Historical Climate Trends in the Study Area

The climate of the basin is dominated by Inter Tropical Convergence Zone (ITCZ) and can be greatly influenced by El Nino (ENSO Index) and the Indian Ocean Dipolee (IOD) during some seasons [17]. The main rainy season from June to September accounts for $70 \%$ to $90 \%$ of the annual rainfall with the remaining $30 \%$ to $10 \%$ falling in the dry season from October to May. The mean annual rainfall ranges $1407 \mathrm{~mm}$ to $2297 \mathrm{~mm}$ (1983-2012) in this watershed. There is high diurnal variation in temperature between the daily maximum and minimum [17]. The annual mean daily minimum and maximum temperature at the Dangila (1993-2012) weather station in this watershed is $9.1^{\circ} \mathrm{C}$ and $25.1{ }^{\circ} \mathrm{C}$, respectively, whereas the annual mean temperature $(1983-2012)$ is $17.2{ }^{\circ} \mathrm{C}$.

\subsection{Methodology}

\subsubsection{Data}

Daily rainfall for 20 years (1993-2012) from Dangila, Bahir Dar, Sekela, Wetet Abay and Enjabara stations and daily temperature data from Danigla and Bahir Dar weather stations were collected from National Metrological Agency (NMA). Hydrological records of 20 years daily river discharge data were collected from Ministry of Water, Irrigation, and Energy (MoWIE) (see Figure 1, where weather stations are indicated with diamond symbols and river gauges are with triangle symbols). 
Missing rainfall data were estimated from neighboring closer station using inverse distance weighting procedure as described by Dingman [18]. In addition Landsat images (SAT IMAGE) with a resolution of $90 \mathrm{~m} \times 90 \mathrm{~m}$ were used to delineate the watershed and to prepare the land use/cover map of the basin using Arc GIS 10.1 (ESRI, Redlands, CA, USA).

\subsubsection{Impact Assessment Framework}

The impact of climate change on the future hydrology of the Gilgel Abbay watershed for both periods of 2021-2040 and 2081-2100 was investigated for high (RCP 8.5) and medium-low (RCP 4.5) with 1980-1999 considered as the baseline period. A schematic diagram showing the major steps followed in the study can be seen in Figure 2. First, 20 years of daily weather data were collected, in parallel with ratios in monthly precipitations and differences in monthly temperatures between projections and baseline retrieved from seven GCMs with RCP 8.5 and RCP 4.5. Second, 200 samples of 1-year daily data were generated by a weather generator for both the baseline and projected weather data. Third, the generated daily weather data drove the calibrated hydrological model for the baseline and future periods respectively. Finally, impact assessment was evaluated by comparing the baseline and the projected monthly runoffs.

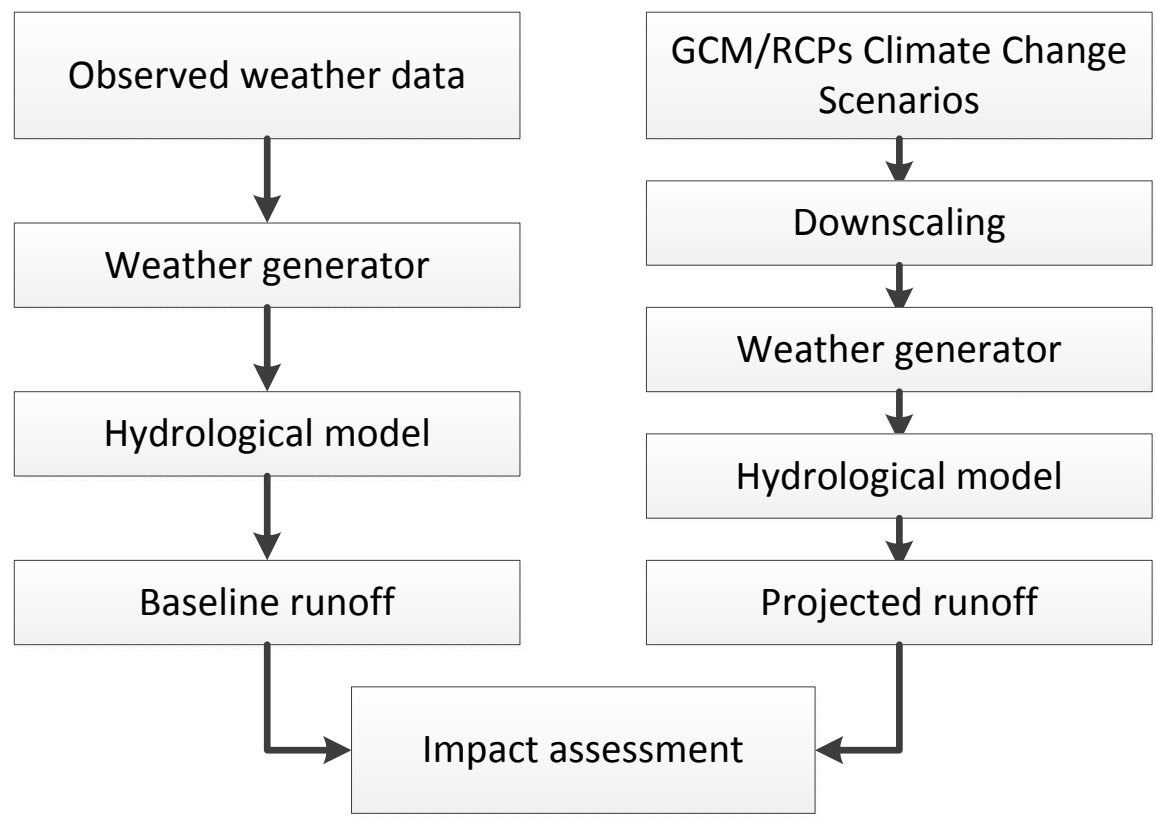

Figure 2. Methodology framework of impact assessment.

\subsubsection{Climate Change Scenarios}

Selection of GCMs

A total of 7 GCMs, including CCSM4, CESM1-CAM5, GFDL-ESM2G, HADGEM2-AO, IPSL-CM5A-MR, MIROCS and NoR-ESM1-M, were selected as having strong correlations with the baseline climatology in precipitation and temperature of Gilgel Abbay watershed. The GCMs projections obtained from CMIP5 based upon the RCPs are applied in this study. The RCPs of IPCC AR5 [2] are the prescribed concentration pathways for greenhouse gasses and aerosols, together with land use change that are consistent with a set of broad climate outcomes used by the climate modeling community. They are calculated based on the concentration pathway that approximates the level of radiative forcing $\left(\mathrm{W} / \mathrm{m}^{2}\right)$ at the end of the 21st century [19]. Both RCP 8.5 and RCP 4.5 in association with 7 GCMs projections were downloaded from the IPCC data distribution center for this study. The RCP 8.5 is characterized by increasing greenhouse gas emissions over time, representative of 
scenarios from the literature that lead to high greenhouse gas concentration levels [20], whereas RCP 4.5 is characterized by a stabilization scenario in which total radiative forcing is stabilized shortly after 2100, without overshooting the long-run radiative forcing target level [21,22]. This paper uses climate change scenario data for a short-term (2021-2040) and a long-term projection period (2081-2100). Comparisons are made of projections of precipitation and temperature changes by seven models with two RCPs and two periods for both wet and dry-seasons.

Downscaling

The output of GCMs cannot directly be used in hydrological studies due to their coarse resolution. In this study, a simple downscaling approach [23], considering the changes between the baseline simulated and the future climate projected at the nearest GCMs grid to be adopted as the changes at the local grid, was employed to model changes in the Gilgel Abbay watershed. The ratios in monthly precipitations of the future climate to the baseline simulated at the nearest GCMs grid are used to multiple observed monthly precipitations of local watersheds for estimating future monthly precipitations. For seven GCMs considered in this study, locations of the nearest grids to Gilgel Abbay watershed are different due to dissimilar spatial resolutions among GCMs. Temporal downscaling by a weather generator was employed to generate multi-samples of daily weather to facilitate runoff simulations. The daily temperature is generated using the first order Markov chains, while the daily precipitation is generated in two steps that involve a random process of determining rainfall occurrence and an exponential distribution of generating rainfall amounts [23]. For both baselines and future climate change scenarios, a series of 200-year samples of daily precipitation and temperature realizations were generated for use as input for GWLF hydrological model to simulate runoffs.

\subsubsection{Hydrological Model}

A physical based GWLF [13] hydrological model is used to simulate the water budget of Gilgel Abbay watershed. Data from 5 weather stations in this watershed (indicated with diamond symbols in Figure 1) were used to estimate the basin averaged precipitation with the Thiessen polygon method. Daily water balances are computed for unsaturated zones as well as shallow saturated zones. Monthly calculations are made for surface runoff based on the daily water balance accumulated to monthly values, whereas the seasonal surface runoff is determined based on the monthly water balance accumulated in the wet-season (June to September) and dry-season (October to May). The model was calibrated and validated using 20 years of observed flow data (1993 to 2012) for the Gilgel Abbay River. Both baseline and projected monthly runoffs were then calculated as the ensemble average of 200 realizations of daily runoffs calculated by the GWLF with 200 samples of daily weather data generated for baseline and climate projection, respectively.

\section{Results}

\subsection{Temperature}

As shown in Figure 3, the projected temperature increases an average of $1.6^{\circ} \mathrm{C}$ over the short-term period 2021-2040 and nearly $4{ }^{\circ} \mathrm{C}$ over the long-term period 2081-2100, as predicted with the CCSM4, HADGEM-AO, IPSL-CM5A-MR and GFDL-ES2MG. Similar trends can be found for the other three GCMs, although there are minor differences in the magnitudes. In both time periods, the magnitude is higher for the higher emission scenarios of RCP 8.5 than for the medium-low emission scenarios of RCP 4.5. The RCP 8.5 pathway arises from little effort being made to reduce emissions and represents a failure to curb warming by 2100 , whereas RCP 4.5 indicates a stabilizing of total radiative forcing by the application of a range of technologies and strategies for reducing greenhouse gas emissions. 

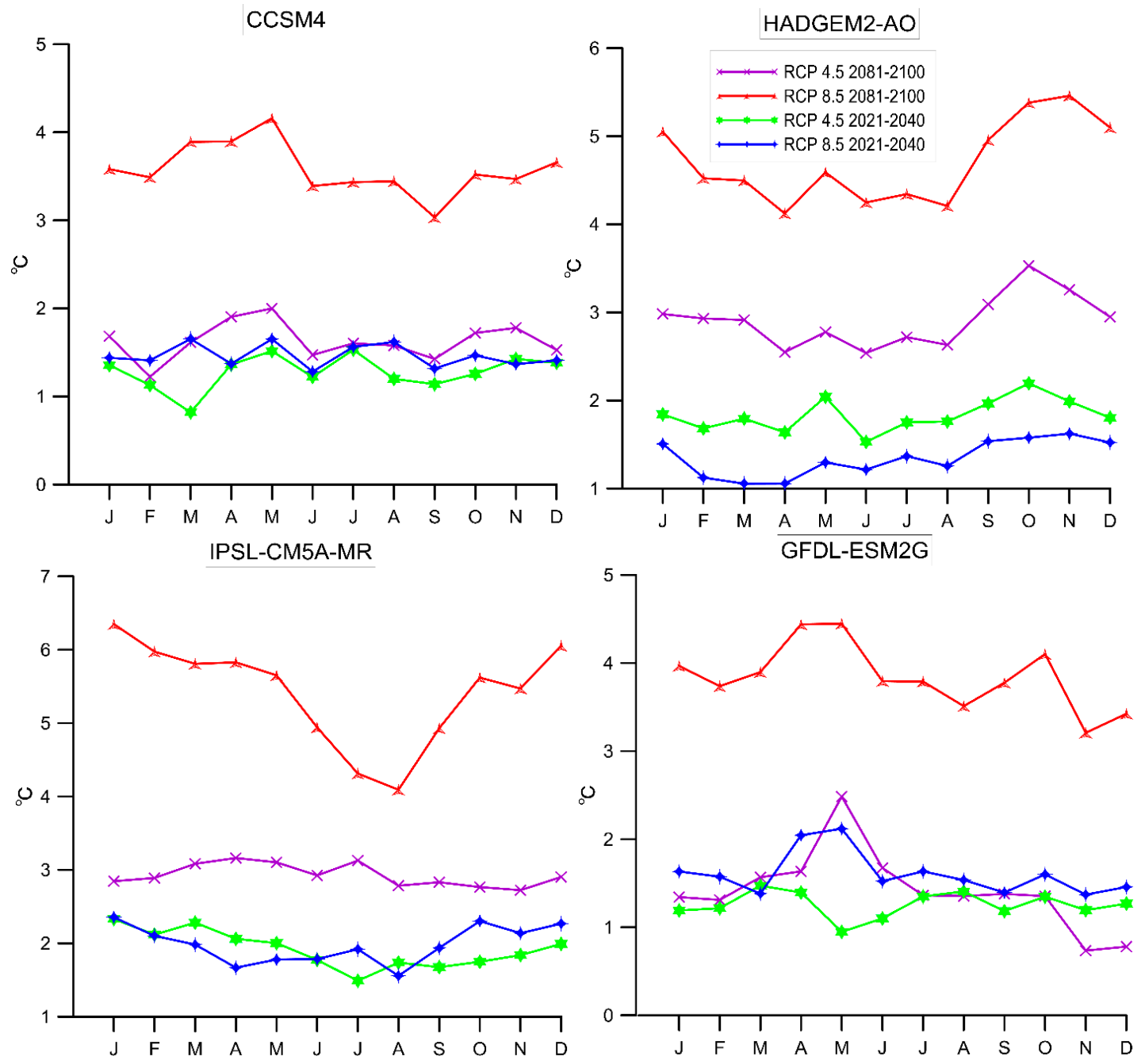

Figure 3. Projected change in mean temperature at Gilgel Abbay watershed for 2021-2040 and 2081-2100 time windows under RCP 8.5 and RCP 4.5 (Representative Concentration Pathway, 4.5 and 8.5 are used for medium-low and high emission scenarios, respectively).

\subsection{Precipitation}

For simplicity, the projected changes in precipitation, evapotranspiration and runoff depth are presented separately for the wet season and dry season. The results are given as a percentage change of the projected with respect to the baseline (e.g., a change of $100 \%$ would imply a doubling of precipitation/runoff depth). As shown in Figure 4 and Table 1, we found a general decrease of precipitation in the dry-season and a general increase in wet-season with most GCMs, except for HADGEM2-AO and MIROC5 in dry-season and HADGEM2-AO in wet-season, for both RCPs and both time windows. The dry-season decrease ranges $4 \%$ to $25 \%$ and the wet-season increase ranges $5 \%$ to $23 \%$.

The largest percentage increase (23\%) from the baseline is observed with the MIROC5 GCM under RCP 8.5 in the long-term time window, while HADGEM2-AO yields the largest projected dry season decrease (25\%), again under RCP 8.5 within the same time window. The ensemble average of five out of seven GCMs (presented in Table 1) shows a 15\% decrement in the dry season and a 15\% increment in the wet season with RCP 8.5 over the long-term time windows. 

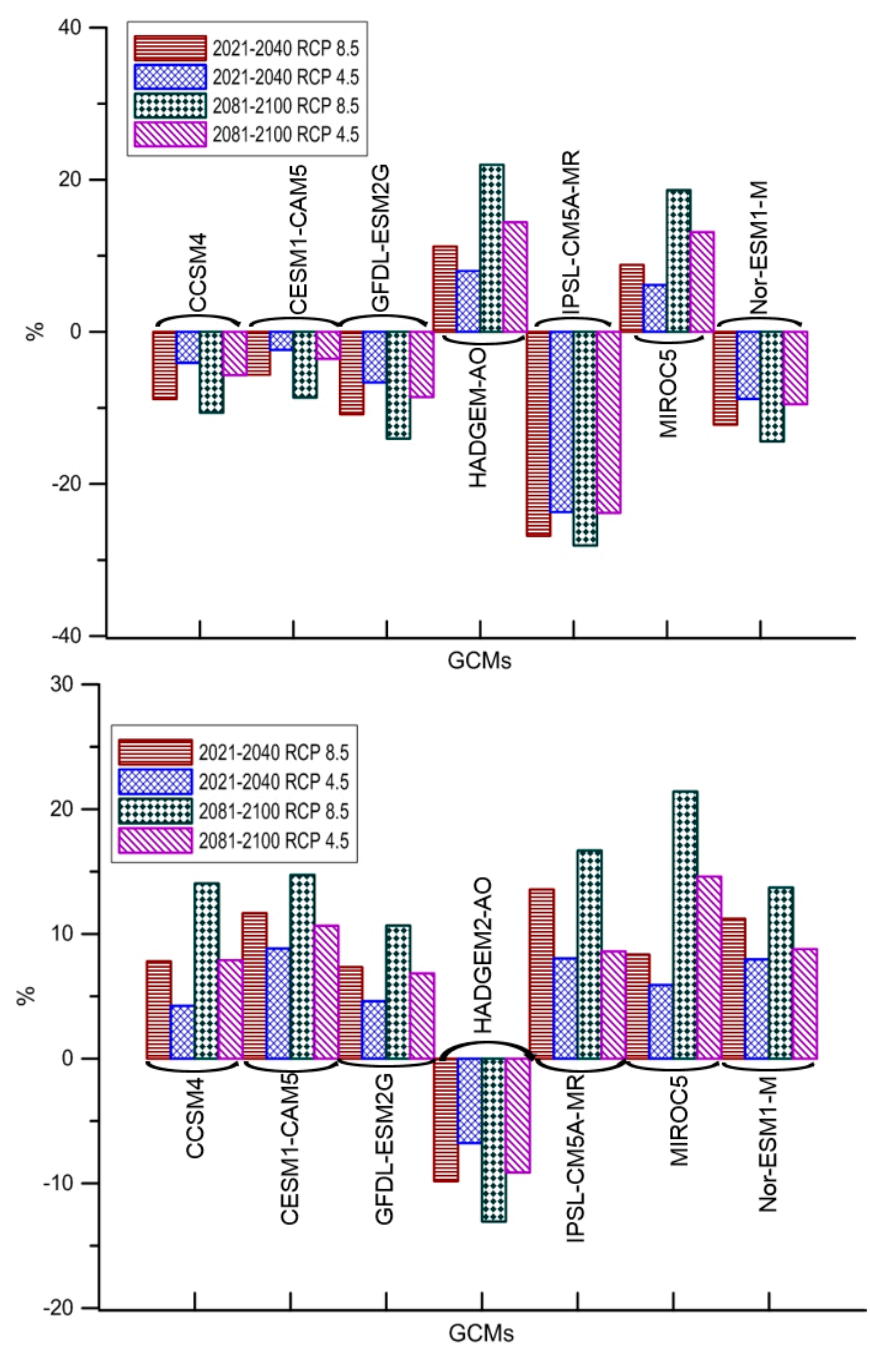

Figure 4. Projected change of precipitation for a period of 2021-2040 and 2081-2100 in dry season (top) and wet season (bottom) of Gilgel Abbay watershed with reference to the baseline (1980-1999) under RCP 8.5 and RCP 4.5 .

Table 1. Percentage of change of projected precipitation (P) and evapotranspiration (ET) with ensemble average of GCMs (Global Circulation Models).

\begin{tabular}{|c|c|c|c|c|c|c|c|c|c|}
\hline \multirow{3}{*}{$\begin{array}{c}\text { Time } \\
\text { Windows }\end{array}$} & \multirow{3}{*}{$\begin{array}{c}\text { Scenarios } \\
\text { (RCPs) }\end{array}$} & \multicolumn{4}{|c|}{ Dry-Season } & \multicolumn{4}{|c|}{ Wet-Season } \\
\hline & & \multicolumn{2}{|c|}{$\mathbf{P}$} & \multicolumn{2}{|c|}{ ET } & \multicolumn{2}{|c|}{$\mathbf{P}$} & \multicolumn{2}{|c|}{ ET } \\
\hline & & $(+), 2$ & $(-), 5$ & $(+), 2$ & $(-), 5$ & $(+), 6$ & $(-), 1$ & $(+), 7$ & $(-), 0$ \\
\hline \multirow{2}{*}{ 2021-2040 } & RCP 8.5 & $10 \%$ & $13 \%$ & $9 \%$ & $17 \%$ & $10 \%$ & $10 \%$ & $12 \%$ & 0 \\
\hline & RCP 4.5 & $7 \%$ & $9 \%$ & $6 \%$ & $13 \%$ & $7 \%$ & $7 \%$ & $9 \%$ & 0 \\
\hline \multirow{2}{*}{ 2081-2100 } & RCP 8.5 & $20 \%$ & $15 \%$ & $17 \%$ & $20 \%$ & $15 \%$ & $13 \%$ & $16 \%$ & 0 \\
\hline & RCP 4.5 & $14 \%$ & $10 \%$ & $10 \%$ & $13 \%$ & $10 \%$ & $9 \%$ & $11 \%$ & 0 \\
\hline
\end{tabular}

Notes: P stands for precipitation and ET stands for Evapotranspiration; $(+)$ and $(-)$ shows sign of increment and decrement; and the adjacent number shows the number of GCMs shown projected increment or decrement change with respect to the baseline.

\subsection{Evapotranspiration}

Seasonal changes in evapotranspiration (ET), presented in Figure 5 and Table 1, show a decrease in dry-season ET with all GCMs except HADGEM2-AO and MIROC5 for both RCPs and over both time windows. The changes are severe in the dry-season, up to $-23 \%$ in the NOR-ESM-M GCM with 
RCP 8.5 over the 2081-2100. Projections for the wet-season, substantial increases (6\% to $19 \%$ ) were found with all GCMs for both RCPs and over both time windows. The highest increment occurs with RCP 8.5 over the long-term time window. Evapotranspiration is expected to rise due to elevated temperatures. The projections for the dry season, however, are the other way around. The decrease of ET in the dry-season can be explained by less available water attributed to the decrease in precipitation.

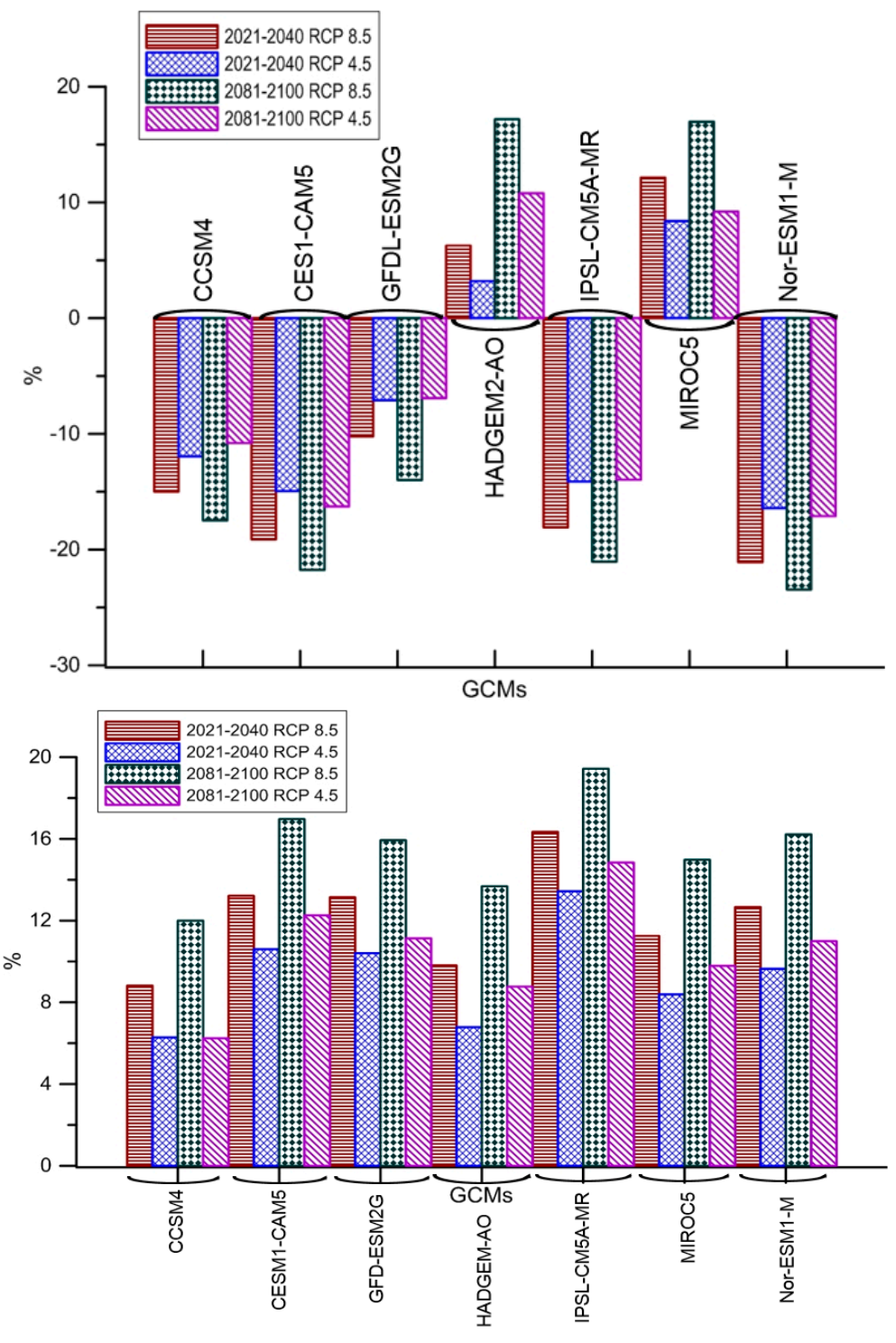

Figure 5. Projected change of evapotranspiration for a period 2021-2040 and 2081-2100 in dry (top) and wet season (bottom) of Gilgel Abbay watershed with reference to the baseline (1980-1999) under RCP 8.5 and RCP 4.5 .

\subsection{Hydrological Model Calibration}

Runoffs simulated by the GWLF were calibrated with observed flows of the Gilgel Abbay River by trial and error. Among the parameters considered for the calibration of the GWLF model, the Soil Conservation Service curve number II, recession constant, initial unsaturated and saturated soil moisture content, and plant cover coefficient were found to be the most sensitive. Results of model performance were evaluated by root mean square error (RMSE $=26.8 \mathrm{~mm} / \mathrm{month}$ ), Nash-Sutcliffe efficiency (NSE $=0.92)$ and coefficient of determination $\left(R^{2}=0.93\right)$, indicating a high correlation between the simulated and observed runoff depths. 


\subsection{Impact of Climate Change on Runoff}

Projected changes of runoff in the dry and wet-seasons under RCP 8.5 and RCP 4.5 are given in Figure 6. A considerable decrease of runoff is shown in five out of seven GCMs in the dry season, and a decrease of reaching $-24 \%$ with the CESM1-CAM5 GCM for the long-term time window is noted. For this later time window, the decline in runoff is higher projected with the RCP 8.5 than those projected with the RCP 4.5 simulations.
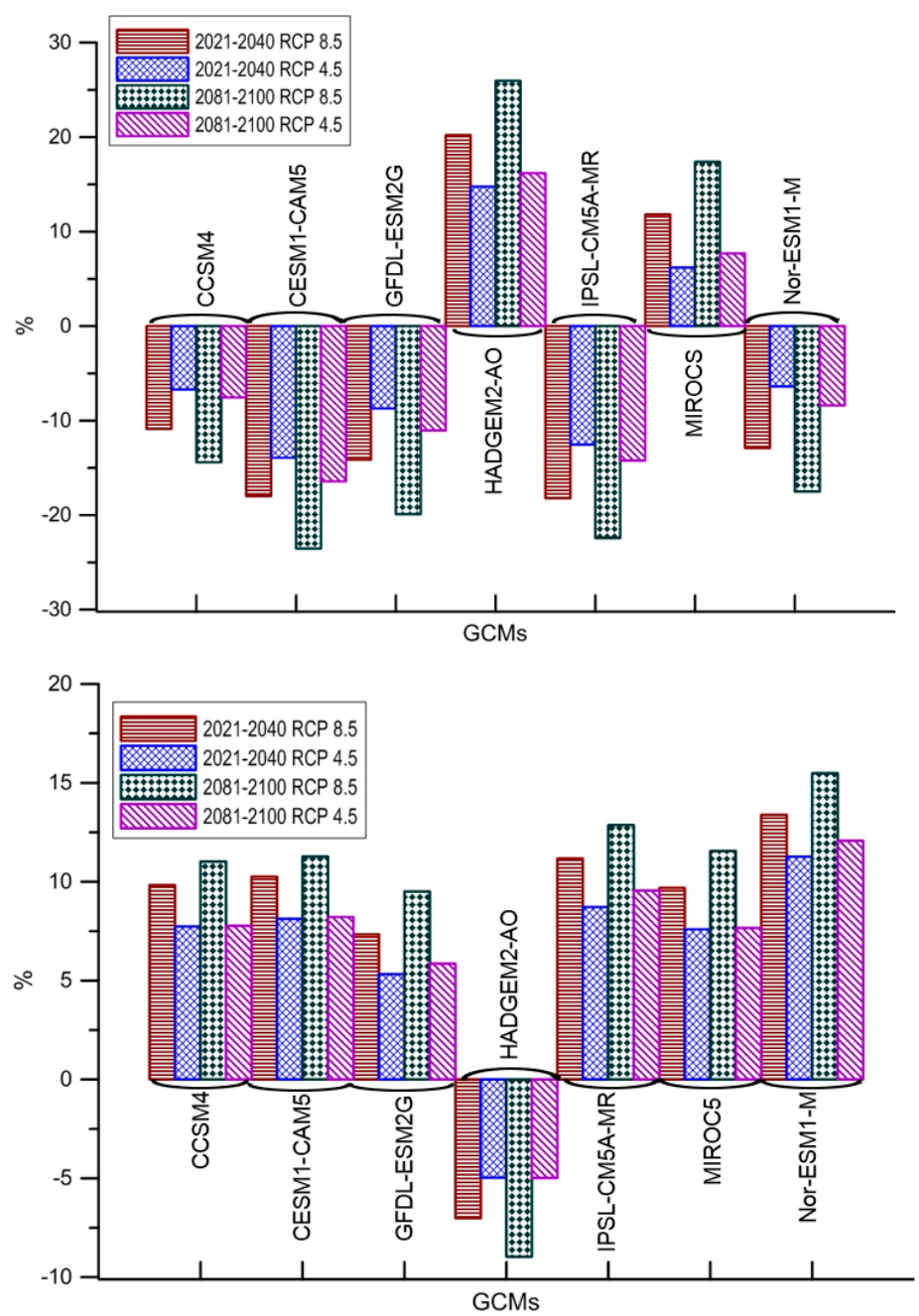

Figure 6. Projected change of runoff for a period 2021-2040 and 2081-2100 in dry (top) and wet season (bottom) of Gilgel Abbay watershed with reference to the baseline (1980-1999) under RCP 8.5 and RCP 4.5.

As depicted in Figure 7, the box plot of projected changes of dry-season runoffs with seven GCMs shows percentages changed in runoffs ranging from $+12 \%$ to $-18 \%$ over $2021-2040$ with RCP $8.5,+6 \%$ to $-13 \%$ over $2021-2040$ with RCP $4.5,+17 \%$ to $-22 \%$ over $2081-2100$ with RCP 8.5 and $+8 \%$ to $-14 \%$ over 2081-2100 with RCP 4.5. The maximum changes of dry-season runoffs occur over 2081-2100 with RCP 8.5, although there is a slight increase projected with both HADGEM2-AO and MIROC5 (see top of Figure 6). On the other hand, except with the HADGEM2-AO, there is a significant increase of projected runoffs compared to the baseline with all GCMs in the wet-season and over both time windows with both RCPs. As shown in Figure 7, the increase ranges from 7\% to 11\% over 2021-2040 with RCP $8.5,5 \%$ to $9 \%$ over $2021-2040$ with RCP $4.5,10 \%$ to $13 \%$ over $2081-2100$ with RCP 8.5 and $6 \%$ to $10 \%$ over 2081-2100 with RCP 4.5. Among these, the highest increase was found in the case of 
RCP 8.5 over the long-term time window. The projected dry season decrease in runoff found with all scenarios and over all time windows is related to the decline in precipitation, whereas the projected increase in runoff in the wet-season is attributed to the increase of precipitation.
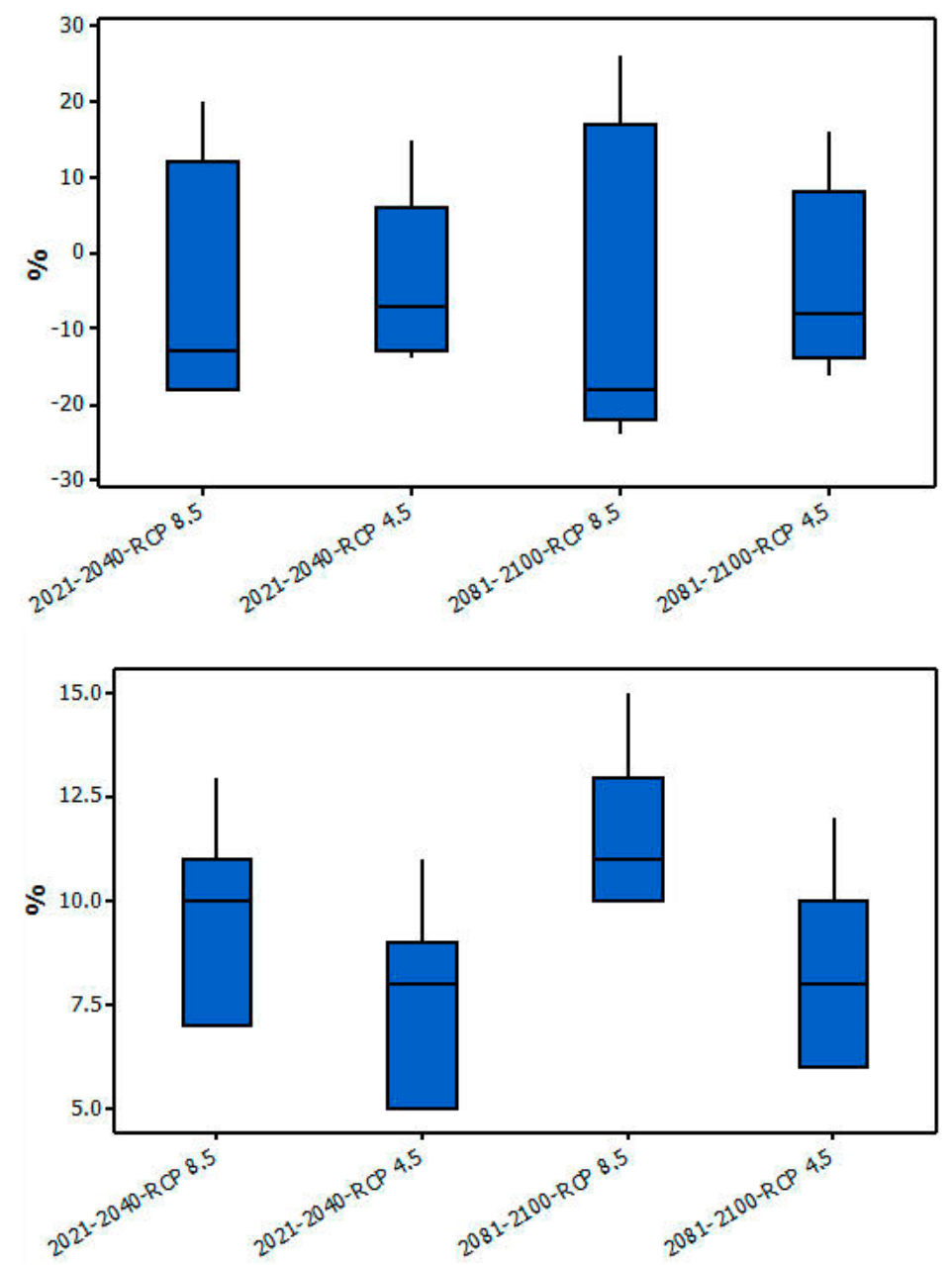

Figure 7. Box plot of projected changes of runoffs with seven GCMs in dry (top) and wet (bottom) seasons.

\section{Seasonal Variability of Flow}

Seasonal variability of flow is crucial to the available water resources and aquatic activities (e.g., navigation and ecotourism). This is explained by the Seasonal Variability Index (SVI) of flow. SVI is used as an indicator for measuring the seasonal variability of flow, which is defined as a percentage of the average seasonal flows during the months of June-September to the sum of annual runoff calculated as the following,

$$
S V I=\left[\frac{Q_{\text {June }}+Q_{\text {July }}+Q_{\text {August }}+Q_{\text {September }}}{\sum_{j=J a n .}^{\text {Dec. }} Q_{j}}\right] \times 100 \%
$$

The results of calculated SVIs are presented in Figure 8. Projected calculations of SVIs with most GCMs show higher values compared to the baseline except for HAD-GEM-AO, and MIROC5 projects values nearly equivalent to the baseline. The SVI values are extremely high when projected with RCP 8.5 over the long-term time window. 


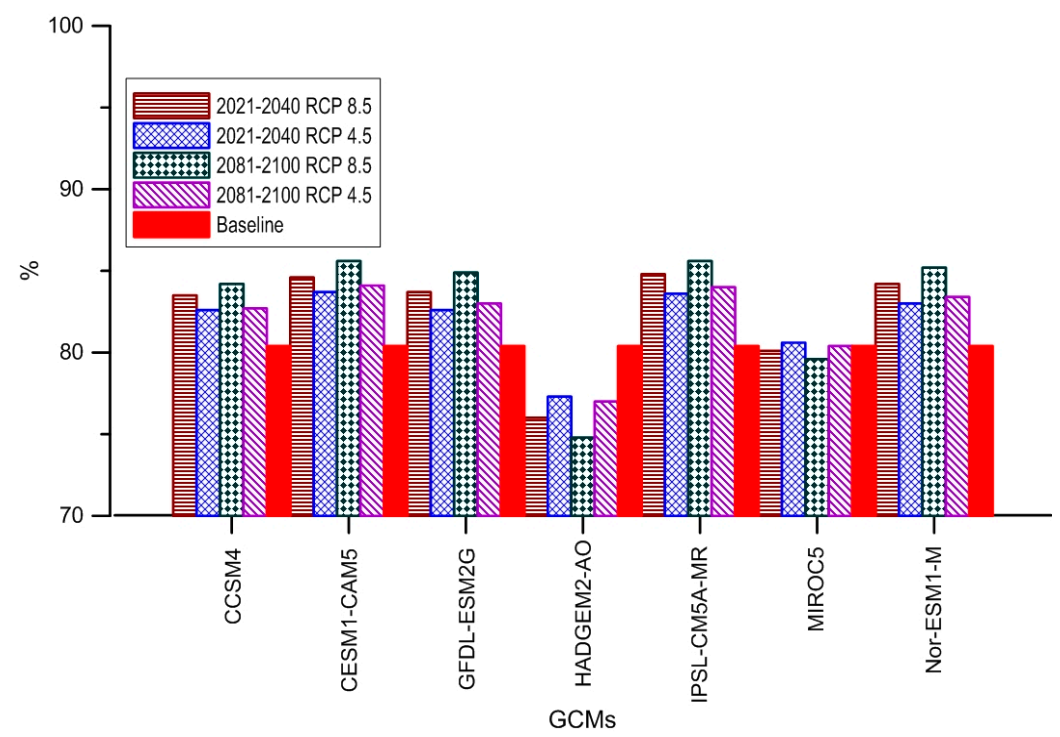

Figure 8. Seasonal Variability Index of flow in percentages with different GCMs and RCPs over two periods compared to that of the baseline.

Taking projected seasonal rainfall pattern of CCSM4 GCM as an example (see Figure 9), a slight decrease at the beginning and an increase at the end of the rainy season in comparison with the baseline were observed, which explains the seasonal variability of projected flow as presented in Figure 10. Such change of shifted seasonal pattern was also found for the other six GCMs.
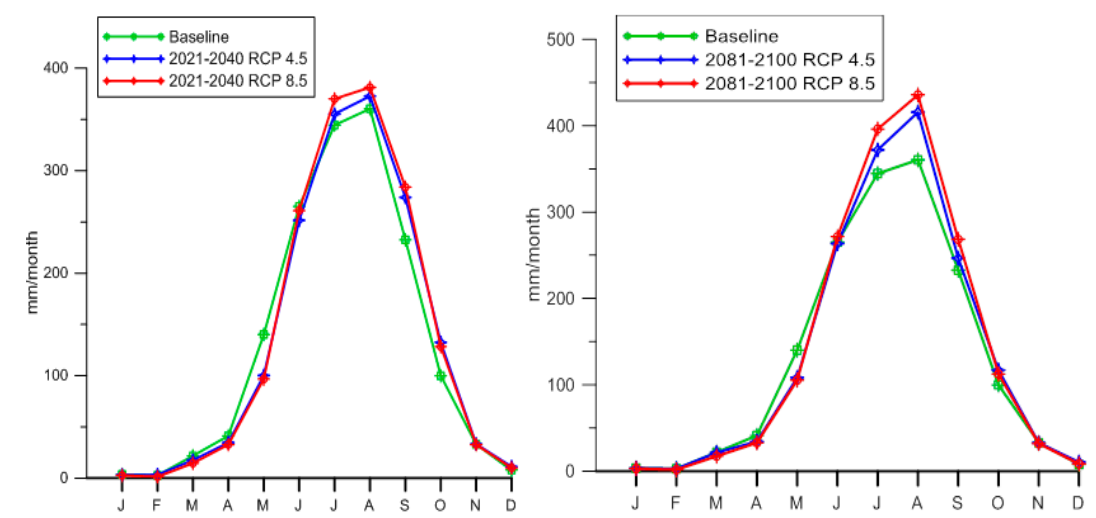

Figure 9. CCSM4 GCM projected monthly precipitation compared to the baseline.

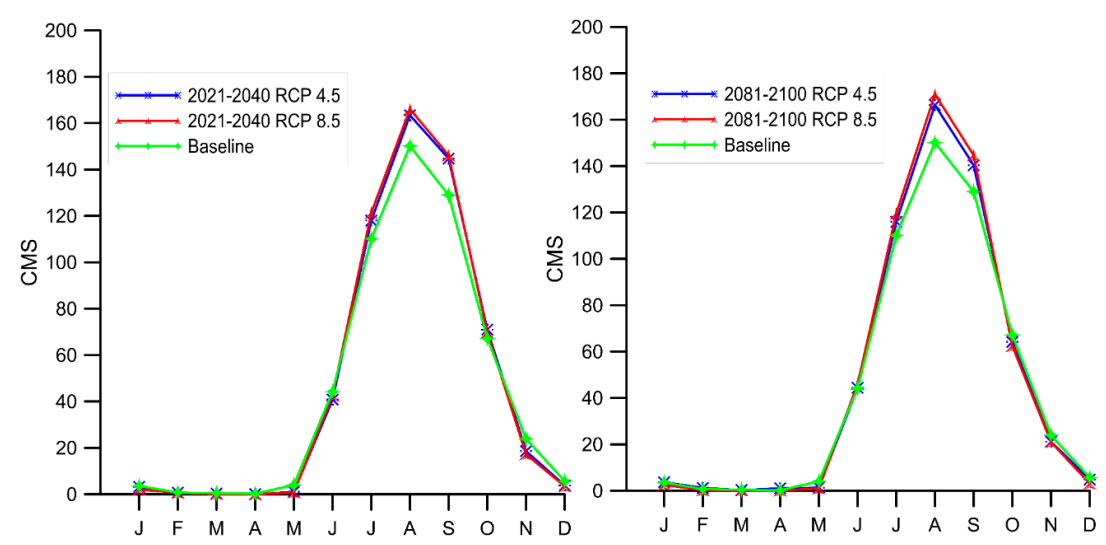

Figure 10. CCSM4 GCM projected monthly flow in cubic meter per second compared to the baseline. 


\subsection{Possible Impact on Lake Storage and Irrigation Scheme}

Table 2 presents runoff contributions of Gilgel Abbay to lake storage estimated with an active lake storage of $9100 \mathrm{Mm}^{3}$. Under current condition, runoff of Gilgel Abbay accounts for $19.5 \%$ of total lake storage. An ensemble average of seven GCMs projections shows increased contributions of $4.2 \%$ to $5.5 \%$ as given in Table 2. The outflow regulated for hydropower generation is within $3 \mathrm{~m}$ range (1784 masl to 1787 masl) after fully operations of Tis Abay I and II power plants in 2001 [14]. Increased contributions to lake storage shows a good opportunity to maintain its minimum operating level of 1784 masl [24] for producing hydropower.

Table 2. Runoff contribution of Gilgel Abbay to Lake storage.

\begin{tabular}{ccccc}
\hline Current Contribution & \multicolumn{4}{c}{ Percent Increase in Projected Contribution } \\
\hline \multirow{2}{*}{ Volume percentage } & \multicolumn{2}{c}{$2021-2040$} & \multicolumn{2}{c}{$2081-2100$} \\
\cline { 2 - 5 } & RCP 8.5 & RCP 4.5 & RCP 8.5 & RCP 4.5 \\
\hline 19.5 & 5.2 & 4.2 & 5.5 & 4.3 \\
\hline
\end{tabular}

Note: Estimated with an active lake storage of $9100 \mathrm{Mm}^{3}$.

Changes of runoff also have significant impacts on the scheme demand of irrigation water in the Gilgel Abbay watershed. Figure 11 depicts the irrigation water demand and the available water at mean monthly scale over 1993-2012. High irrigation water demand appears in dry-season when the available water gets lower, whereas the demand is low in wet-season and the available water gets higher. Shortage of irrigation water in dry-season is compensated by pumping groundwater in areas away from lake or taking lake water in areas with irrigation systems. Similar to projected runoffs presented in Section 3.5, increasing runoff in wet-season and decreasing in dry-season will amplify such irrigation shortage in dry-season. Better water allocation and management strategies should be evaluated and implemented to against problematic food security due to water shortage.

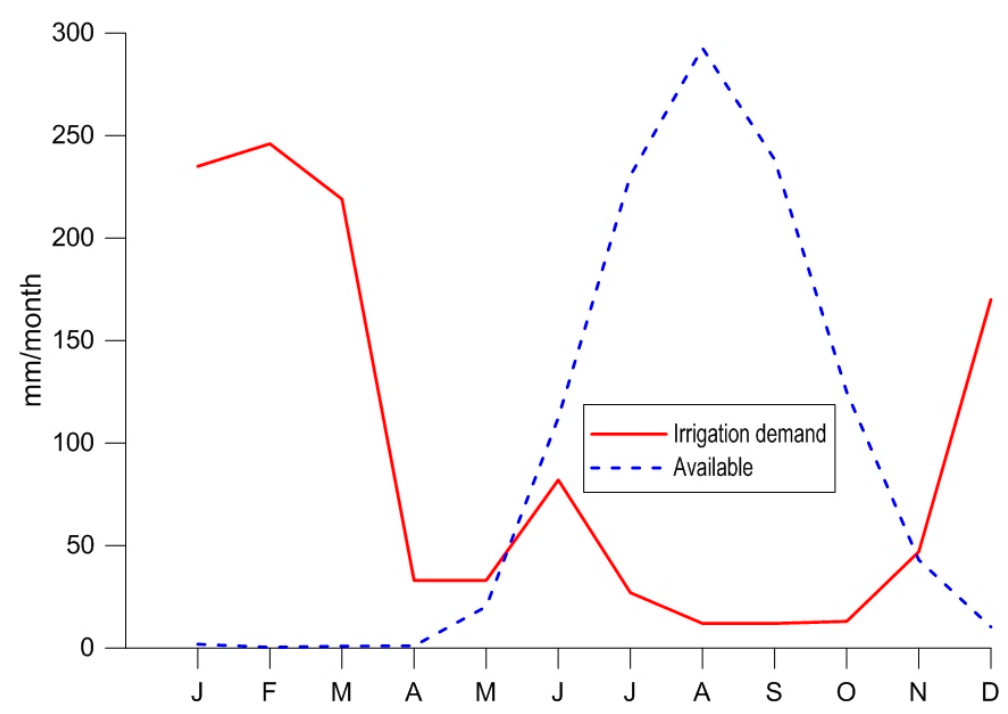

Figure 11. Scheme of Irrigation demand in mean monthly and available water in Gilgel Abbay watershed (long term average of 1993-2012); where the irrigation demand scheme is obtained from Tana sub basin research center in mean monthly, Bahir Dar, Ethiopia.

\section{Discussion}

In this study, projected temperatures of two scenarios over two time windows are compared to the baseline climatology. The increase in temperature in average about $1.6^{\circ} \mathrm{C}$ and $4{ }^{\circ} \mathrm{C}$ in the 
short and long term time windows respectively lies in the range of temperature projected in the Fifth IPCC assessment report [2] for Africa's future climate trends. In IPCC (2014), [2] (p. 1202) "under a high-emissions scenario, average temperatures will rise more than $2{ }^{\circ} \mathrm{C}$, the threshold set in current international agreements, over most of the continent by the mid-21st century. Average temperatures will rise more than $4{ }^{\circ} \mathrm{C}$ across most areas by the late 21 st century". Thus, the projected temperature especially with the higher emission scenarios (e.g., RCP 8.5) over the long term time window (2081-2100) tends to have a relatively higher magnitude, which in turn is likely to produce higher evapotranspiration over the entire watershed. This may contribute to the decline of soil moisture during the dry-season when the basin experiences low rainfall.

In Section 3.2, we find a general decrease of precipitation in dry-season and a general increase in wet-season with most GCMs in associations with RCP 8.5 and RCP 4.5 over both the short (2021-2040) and long term (2081-2100) time windows. These results are consistent with Eneyew et al. [17] who reported changes in rainfall amounts of $2.6 \%$ and 5.7\% (for periods of 2021-2050 and 2071-2100) based on ECHAM and IPSL GCMs, respectively, in the rainy season (June-September) for the Lake Tana basin. The decrease in precipitation, especially in the dry-season, combined with the increase of temperature is likely to have a considerable effect on runoff.

Substantial increases of evapotranspiration were found with all GCMs for both RCPs over both time windows in the wet season whereas a decrease in dry-season (see Figure 5). In arid and semi-arid regions, ET is often limited seasonally by the availability of soil water in addition to temperature $[25,26]$. Although temperature is projected to increase in both seasons, results of projected evapotranspiration in dry-season follows the pattern of the projected precipitation due to limited available water.

Based on our runoff projections (see Figure 6), a considerable decrease of runoff was shown with most GCMs in the dry season while there is a significant increase compared to the baseline with all GCMs in the wet-season over both time windows for both RCPs. These are similar to the findings reported by UNECA [27], an increase of water resources by about $10 \%$ in east Africa including Ethiopia is predicted at the end of the 21st century. This trend also corroborates the findings of Setegen et al. [7] that the dominant factor controlling runoff depth in the Tana basin is precipitation rather than evapotranspiration. Similarly, Babatolu et al. [28] reported a high positive correlation between annual precipitation and annual runoff depth in east Africa. Our projection also reveals that precipitation is the dominating factor affecting runoffs of the Gilgel Abbay watershed. This conclusion is also substantiated by the seasonal variability of flow calculated by SVI indices as shown in Figure 8 .

In 2003, the lowest lake level ever recorded in history was observed (dropped below 1785 masl, the minimum lake level for navigation), navigation ceased for four months, and the outflow significantly declined [29]. Seasonality variability of inflow has critical effects to the lake storage and discharge capacity. As projected runoff shows decrease in dry-season, there might be a great chance to regulate water withdrawal from the lake even below 1785 masl in dry-season as what happened in 2003 to sustain the supply of water for hydropower generations and demands. Water resource managers/policy makers should seek other alternative water resources like ground water to meet the scheme irrigation water demand in dry-season.

Annual runoff of Gilgel Abbay accounts for 28.5\% of total inflows to the lake [30], which has a significant impact on hydropower generation and irrigation water demands. Tana basin and its adjacent catchments have been identified as one of growth corridors in the country and integrated water resources plan is being implemented [14]. Facing possible challenges associated with climate changes, all results should be exercised with care for the implementation of adaption measures because of uncertainties in emission scenarios as well as projections from different GCMs [31].

\section{Conclusions}

Climate change and variability have great potential to impose pressures on water availability and accessibility in Africa. The impact is likely to be more pronounced in regions like the Horn of Africa. This study assessed the impact of climate change on the Gilgel Abbay watershed that drains 
into Lake Tana, in the upper Blue Nile basin. Climate impact on watershed hydrology was assessed using a physically based GWLF hydrological model. Seven GCMs, in conjunction with both RCP 8.5 and RCP 4.5 from CMIP5 were adopted for both periods of 2021-2040 and 2081-2100. A weather generator was employed to generate daily temperature and precipitation based on different climate scenarios by modifying temperature and precipitation climatology. The generated daily temperature and precipitation data were fed into the GWLF to simulate runoff depths affected by climate change.

In all cases, projected changes in magnitudes of hydrological components were higher with the RCP 8.5 scenario compared to those with the RCP 4.5 scenario. Rising temperature was consistently found in both time windows and RCPs from most of the GCMs, whereas increases of precipitation, ET and runoff were projected by six GCMs for the wet-season. Declining precipitation, ET and runoff in the dry-season could be expected with all GCMs, except HADGEM2-AO and MIROC5. Changes of runoffs are mainly dominated by the variations in projected precipitation. Especially in the long-term, increasing precipitation in the wet-season would make it wetter resulting higher runoff in the watershed. This will have deleterious consequences in the near future on the local community as the watershed is naturally vulnerable to frequent flash floods. On the other hand, increase runoff in the Gilgel Abbay Rivers may offer a good opportunity to contribute more inflow to lake storage, discharge for hydropower generation, and water for irrigation practices. However, the decrease of river flow in dry-season may intensify the existing shortage of irrigation water and requires better adaption measures to prevent possible food security due to water shortage. The predicted magnitudes vary among models and scenarios as in other climate related studies. Future studies aimed at building adaptation measures based on impact assessment of climate change should be aware of uncertainties in climate projections. The concept of adaption pathways to periodically evaluating the applicability of adaption measures and amending correspondent actions accordingly may provide advantages of building flexible and adapted measures in view of uncertainties in climate projections.

Acknowledgments: This study was supported by the Ministry of Science and Technology, Taiwan (R.O.C.) under the Contract No. MOST-104-2116-M-008-018 and MOST-104-2621-M-002-002 with the National Central University. Field data were provided by the National Metrological Agency and Ministry of Water, Irrigation, and Energy of Ethiopian. English proofreading of this paper was gratefully helped by Debbie Nester.

Author Contributions: Hailu Sheferaw Ayele conducted the simulation and wrote the paper. Ming-Hsu Li designed the assessment framework and help modify the paper. Ching-Pin Tung helped designed the assessment framework and results discussions. Tzu-Ming Liu provided technical supports on impact assessments.

Conflicts of Interest: The authors declare no conflict of interest.

\section{References}

1. Team, C.W.; Pachauri, R.; Reisinger, A. Contribution of Working Groups I, II and III to the Fourth Assessment Report of the Intergovernmental Panel on Climate Change; IPCC: Geneva, Switzerland, 2007.

2. Pachauri, R.K.; Allen, M.; Barros, V.; Broome, J.; Cramer, W.; Christ, R.; Church, J.; Clarke, L.; Dahe, Q.; Dasgupta, P. Climate Change 2014: Synthesis Report. Contribution of Working Groups I, II and III to the Fifth Assessment Report of the Intergovernmental Panel on Climate Change; IPCC: Geneva, Switzerland, 2014.

3. Falloon, P.D.; Betts, R.A. The impact of climate change on global river flow in HadGEM1 simulations. Atmos. Sci. Lett. 2006, 7, 62-68. [CrossRef]

4. Mbaye, M.L.; Hagemann, S.; Haensler, A.; Stacke, T.; Gaye, A.T.; Afouda, A. Assessment of climate change impact on water resources in the upper senegal basin (West Africa). Am. J. Clim. Chang. 2015, 4, 77-93. [CrossRef]

5. Omambia, C.S.; Gu, Y. The cost of climate change in Tanzania: Impacts and adaptations. J. Am. Sci. $2010,6$. [CrossRef]

6. Nicholson, S.E.; Yin, X. Rainfall conditions in equatorial East Africa during the nineteenth century as inferred from the record of lake victoria. Clim. Chang. 2001, 48, 387-398. [CrossRef]

7. Setegn, S.G.; Rayner, D.; Melesse, A.M.; Dargahi, B.; Srinivasan, R. Impact of climate change on the hydroclimatology of Lake Tana Basin, Ethiopia. Water Resour. Res. 2011, 47. [CrossRef] 
8. Fang, G.; Yang, J.; Chen, Y.; Zhang, S.; Deng, H.; Liu, H.; De Maeyer, P. Climate change impact on the hydrology of a typical watershed in the Tianshan Mountains. Adv. Meteorol. 2015, 2015, 960471. [CrossRef]

9. Tan, M.L.; Ficklin, D.L.; Yusop, Z. Impacts and uncertainties of climate change on streamflow of the Johor River Basin, Malaysia using a CMIP5 General Circulation Model ensemble. J. Water Clim. Chang. 2014, 5, 676-695. [CrossRef]

10. Beyene, T.; Lettenmaier, D.P.; Kabat, P. Hydrologic impacts of climate change on the Nile River Basin: Implications of the 2007 IPCC scenarios. Clim. Chang. 2010, 100, 433-461. [CrossRef]

11. Abdo, K.; Fiseha, B.; Rientjes, T.; Gieske, A.; Haile, A. Assessment of climate change impacts on the hydrology of gilgel abay catchment in Lake Tana Basin, Ethiopia. Hydrol. Process. 2009, 23, 3661-3669. [CrossRef]

12. Thornes, J.E.; IPCC. Climate Change 2001: Impacts, Adaptation and Vulnerability, Contribution of Working Group II to the Third Assessment Report of the Intergovernmental Panel on Climate Change; Mccarthy, J.J., Canziani, O.F., Leary, N.A., Dokken, D.J., White, K.S., Eds.; Cambridge University Press: Cambridge, UK; New York, NY, USA, 2001; p. 1032.

13. Haith, D.A.; Mandel, R.; Wu, R.S. GWLF, Generalized Watershed Loading Functions, Version 2.0, User's Manual; Department of Agricultural \& Biological Engineering, Cornell University: Ithaca, NY, USA, 1992.

14. McCartney, M.; Alemayehu, T.; Shiferaw, A.; Awulachew, S. Evaluation of Current and Future Water Resources Development in the Lake Tana Basin, Ethiopia; IWMI: Colombo, Sri Lanka, 2010; Volume 134.

15. Easton, Z.; Fuka, D.; White, E.; Collick, A.; Biruk Ashagre, B.; McCartney, M.; Awulachew, S.; Ahmed, A.; Steenhuis, T. A multi basin SWAT model analysis of runoff and sedimentation in the Blue Nile, Ethiopia. Hydrol. Earth Syst. Sci. 2010, 14, 1827-1841. [CrossRef]

16. Federal Democratic Republic of Ethiopia Population Census Commission (FDREP). Summary and Statistical Report of the 2007 Population and Housing Census; UNFPA: Addis Ababa, Ethiopia, 2008.

17. Enyew, B.; Van Lanen, H.; Van Loon, A. Assessment of the impact of climate change on hydrological drought in Lake Tana catchment, Blue Nile Basin, Ethiopia. J. Geol. Geosci. 2015, 2014. [CrossRef]

18. Dingman, S.L. Physical Hydrology; Prentice Hall: Upper Saddle River, NJ, USA, 2002.

19. Meinshausen, M.; Smith, S.J.; Calvin, K.; Daniel, J.S.; Kainuma, M.; Lamarque, J.; Matsumoto, K.; Montzka, S.; Raper, S.; Riahi, K. The RCP greenhouse gas concentrations and their extensions from 1765 to 2300. Clim. Chang. 2011, 109, 213-241. [CrossRef]

20. Riahi, K.; Rao, S.; Krey, V.; Cho, C.; Chirkov, V.; Fischer, G.; Kindermann, G.; Nakicenovic, N.; Rafaj, P. RCP 8.5-A scenario of comparatively high greenhouse gas emissions. Clim. Chang. 2011, 109, 33-57. [CrossRef]

21. Thomson, A.M.; Calvin, K.V.; Smith, S.J.; Kyle, G.P.; Volke, A.; Patel, P.; Delgado-Arias, S.; Bond-Lamberty, B.; Wise, M.A.; Clarke, L.E. RCP 4.5: A pathway for stabilization of radiative forcing by 2100. Clim. Chang. 2011, 109, 77-94. [CrossRef]

22. Wise, M.; Calvin, K.; Thomson, A.; Clarke, L.; Bond-Lamberty, B.; Sands, R.; Smith, S.J.; Janetos, A.; Edmonds, J. Implications of limiting $\mathrm{CO}_{2}$ concentrations for land use and energy. Science 2009, 324, 1183-1186. [CrossRef] [PubMed]

23. Tung, C.P.; Liu, T.M.; Chen, S.W.; Ke, K.Y.; Li, M.H. Carrying capacity and sustainability appraisals on regional water supply system under climate change. Br. J. Environ. Clim. Chang. 2014, 4, 27-44. [CrossRef]

24. Snowy Mountains Engineering Corporation (SMEC). Hydrological study of the Tana-Beles Sub-Basin: Surface Water Investigation; SMEC: Melbourne, Australia, 2008.

25. Kurc, S.A.; Small, E.E. Soil moisture variations and ecosystem-scale fluxes of water and carbon in semiarid grassland and shrubland. Water Resour. Res. 2007, 43. [CrossRef]

26. Wilske, B.; Kwon, H.; Wei, L.; Chen, S.; Lu, N.; Lin, G.; Xie, J.; Guan, W.; Pendall, E.; Ewers, B.E. Evapotranspiration (ET) and regulating mechanisms in two semiarid artemisia-dominated shrub steppes at opposite sides of the globe. J. Arid Environ. 2010, 74, 1461-1470. [CrossRef]

27. United Nations Economic Commission for Africa (UNECA); African Climate Policy Centre (ACPC). Climate Change and Water Resources of Africa: Challenges, Opportunities and Impacts; Working Paper 5; UNECA: Addis Ababa, Ethiopia, 2011.

28. Babatolu, J.; Akinnubi, R. Influence of climate change in Niger River Basin development authority area on Niger Runoff, Nigeria. J. Earth Sci. Clim. Chang. 2014, 5, 1-8. [CrossRef]

29. Belete, M.A. Modeling and Analysis of Lake Tana Sub Basin Water Resources Systems, Ethiopia. Ph.D. Thesis, University of Rostock, Rostock, Germany, 2013. 
30. Wale, A.; Rientjes, T.; Gieske, A.; Getachew, H. Ungauged catchment contributions to lake tana's water balance. Hydrol. Process. 2009, 23, 3682-3693. [CrossRef]

31. Li, M.-H.; Tien, W.; Tung, C.-P. Assessing the impact of climate change on the land hydrology in Taiwan. Paddy Water Environ. 2009, 7, 283-292. [CrossRef]

(C) 2016 by the authors; licensee MDPI, Basel, Switzerland. This article is an open access article distributed under the terms and conditions of the Creative Commons Attribution (CC-BY) license (http:/ / creativecommons.org/licenses/by/4.0/). 